\title{
A Comparative Study of English and Chinese Passives from the Perspective of Figure-ground Theory
}

\author{
Bo Li \\ College of International Studies, Southwest University, China
}

\begin{abstract}
This paper tries to explore differences between Chinese and English passives from the perspective of figure-ground theory in cognitive linguistics. Based on the prominent principles in figure-ground theory, it compares the English and Chinese passives from the angle of prototypical and non-prototypical types and aims to find out a better and stronger explanation for the deep mechanism for English and Chinese passives so that promote learners' ability of cross-language contrastive analysis.
\end{abstract}

Index Terms - passives, figure-ground theory, contrastive study

\section{INTRODUCTION}

Passive sentences, a common but extremely complicated linguistic phenomenon, have been a heated research topic at all times for researchers abroad and at home. The study on passives develops very fast and has achieved great success. What's more, the comparative study of English and Chinese Passives also arouses much interest of various scholars who delve in the study for years in different linguistic genres china. However, many linguistic genres, though, offer some explanations for English and Chinese's distinctions, they are lacking a systematic explanation and also fail to explain some specific phenomena. When cognitive linguistics becomes popular in China, scholars start to study English and Chinese Passives from the angle of cognitive linguistics and compare the two kinds in detail as well. Some theories in cognitive semantics have been brought to analyze English and Chinese Passives such as prototype theory (Xiong Xueliang \& Wang Zhijun, 2001; Feng Fang, 2009), grammaticalization (Ni Wei \& Shao Hongzhi, 2004) and construction grammar (Huang Xueqiang, 2011) and so on. This paper, whereas, tries to apply figure-ground theory to do a comparative study of English and Chinese passives.

On the basis of prominence principle, the notion figure-ground theory is first put forward by Danish psychologist Rubin. His well known face/vase illusion experiment proves that what lies behind our inability to see both the face and the vase is a phenomenon called figure and ground segregation, namely, people cannot see both the figure and ground simultaneously. (F. Ungerer \& H.J. Schmid, 2008)

In cognitive linguistics, figure refers to the prominent part during our cognition process; ground refers to the part that is perceived as being less prominent than figure and serves as a soil to figure. Many cognitive linguists claim that the subject and the object can be used to distinguish the figure and the ground in sentences. (William Croft \& D. Alan Cruse, 2004)

As is known to all, the subject sometimes is the prominent part, so we often regard subject as the figure, the object as the ground. For example:

(a) Tom equals me in strength.

(b) I equal Tom in strength.

(c) Susan resembles my sister.

(d) My sister resembles Susan. (Huang Guangping, 2011)

In these two group sentences, the different choices of subject reflect different perspectives which lead to various prominent part and so is the figure. When people read sentence (a) and sentence (c), they will consciously regard Tom in sentence (a) and Susan in sentence (c) as the figure and my sister is the figure and me and my sister in (a) and (c) is the ground. While in sentence (b) and (d), the situation is on the contrary that I and My sister is the figure and Tom and Susan is the ground. Therefore, it is observable that an entity can be prominent as the figure and ignorant as the ground.

In Chinese, for example: (a) 我家在峨眉山附近。(My home is near the E-mei Mountain; wo jia zai e mei shan fu jin.) (b) 峨眉山在我家附近。(E-mei Mountain is near my home; e mei shan zai wo jia fu jin.) (Kuang Fangtao \& Wen $\mathrm{Xu}, 2003)$ In sentence a, the speaker takes "E-mei Mountain" as the ground to describe "my home" as the figure while in sentence b, the speaker put "E-mei Mountain" in the position of the figure and "my home" in the position of the ground.

All in all, the figure-ground theory in Cognitive Linguistics can be used to explain many linguistic phenomena in both Chinese and English in an effective way. Totally this paper is composed of two parts: (a) a contrastive analysis of English and Chinese prototypical passives (b) a contrastive analysis of English and Chinese non-prototypical passives. 
Respectively this paper will discuss English and Chinese passives in detail first and reveal that there exists some similarities of them, which are helpful for English teaching and learning as well as second language acquisition.

\section{English ANd Chinese Prototypical Passives Based on Figure-Ground Theory}

\section{A. English Prototypical Passives}

An English passive as one of the commonest sentence structures in English is widely used in daily life and its own characteristics which that English passives is usually used when there is no need to mention the agent, when the speaker is unwilling to mention the agent, when there is no way out to find out the agent, etc. As we know, English focus on nouns which lies in the beginning of a sentence is regarded as the subject. Generally speaking, the subject is the agent and the object is the patient, so this is the prototype structure in English which is usually called declarative sentence. However, the English passives also follow the principle with only the position exchange of the subject and object in declarative sentence. The prototypical English passives should be: Subject (patient) + BE + V-en (verbal). And the prototypical passives are divided into two subcategories: the agentless passives and the agentful passives.

"The agent is implied in the context in the agentless passive, whereas the agent is overt in the agentful passive. In fact, they express the same proposition. The choice of agentless or agentful passive is determined by the semantic salience which conveys the speaker's perspective and focus. (Zhao Li, 2010)

\section{English Agentless Passives and Figure-ground Theory}

Agentless passives are passive sentences without agent and only with paient passives. Usually, in active sentences, the agent is the figure which needs to be prominent and the patient is the ground that is used to serve as a soil to the agent. For example: (a) The enemy was defeated. (b) The cap was blown away. (Xiong Xueliang \& Wang Zhijun, 2002) In sentence (a) and sentence (b), it is easy to find that the subject in (a) is the object in (b) and the object in (a) is the subject in (a). When we put the figure-ground theory into consideration, the enemy and the cap in (a) and (b) as a patient is the prominent part that the writer or speaker wants to pay much attention for it follows the principle mentioned before that English focus on the subject and nouns which lies in the beginning of a sentence.

If we discuss these two sentences from the perspective of meaning, we may have a better understanding about why we connect the subject (patient) to the figure in prototypical passives. Once we alter the words' order and change those two sentences into declarative sentences, we may find there is the lack of an agent. The sentence will be organized as following: Who (anyone or any group) defeated the enemy (patient); what (the wind or a people) blew away the cup. In sentence (a), people only concern about whether the enemy was defeated or not and do not much care for who defeat them; as the similar situation in (a), the cup in sentence b is people's focus for they do not want to figure out what cause the cap being blown away and what they really concern about is the change of the cup's state. Therefore, in prototypical English passives, the original agent is omitted and turns to be the ground while the original patient as a prominent part is being put the position of the subject when it is transformed into a passive sentence.

\section{English Agentful Passives and Figure-ground Theory}

As a matter of fact, in English, the agentful passives are few. Xiong Xueliang and Wang Zhijun (2002) made a structure for the appearance of the agent in non-prototypical English passives as following: Subject+ BE+ V-en+ Prep.+ noun phrase. An usually English passive which has the agent is few and the preposition is often led by "by" which is put in the last of a sentence. Therefore, the way to analyze the non-agent English passives based on the figure-ground theory does not take effect. It is obvious that the agent in English passives with the appearance of the agent is more important than this in the non-agent English passives. For instance, we are moved by the movie. Here, although we as a patient have been put to the position of the subject, it does not mean that the figure is "we" and "the movie" should be the ground.

On the contrary, "the movie" will be paid much attention. When people are reading or the sentence, they would like to read till the end and find out what caused people to be moved. And their focus is on the "movie "for it is new information for them comparing to "we". Comparing to sentence (a) He was beaten in category B in the prototypical English passive, we can find that in He was beaten, even though we want to know he was beaten by whom? But we still will concentrate more on a current state of "he" that is "was beaten". The first thing come into mind must be "is it true?" and then maybe we will ask "who beat him?" While in we are moved by the movie, if the sentence is only with "we are moved", we will feel kind of weird for we believe that there is something causing us bring moved. When "the movie" appears, we will have a feeling that this is a really complete sentence in meaning.

All in all, when some parts of a sentence is put to the position of beginning, it control the distribution of information and also influence people' understanding to a certain extent, which lead to the distribution of the importance. In English passives, patient is being put to the beginning of a sentence so the importance of the patient is prominent.

\section{B. Chinese Prototypical Passives}

Passives in Chinese are one of the most important and indispensible sentence structure. People in daily life often use passives to express something indirectly for the consideration others' feelings. Chinese passives also are composed of two types: Chinese Agentfless Passives and Chinese Agentful Passives. Generally speaking, people tend to use agentless passive for their focus is basically on the subject as English.

\section{Chinese Agentfless Passives and Figure-ground Theory}


In Chinese, the prototypical passive is expressed by the passive marker bei(被), which evolves from the meaning to sustain. The colloquial counterparts of bei include jiao(叫), rang(让), gei(给), etc. The agent often appears between the passive marker bei and the verb, and the verb is often followed by a complement to indicate the result caused by an action. The function of bei can be summarized as: (a) to designate the NP before it as a patient; (b) to designate the NP which is optional after it as an agent; (c) to designate a causality in the whole construction. (C.-T. James Huang, Y-H. Audrey Li \& Yafri Li, 2009)

Chinese prototypical passives are divided into agentless and agentful passives. In agentless passives as well, there is a paradigm as following: (personal patient) $\mathrm{N}+$ 被 $^{\mathrm{V}} \mathrm{V}$, for example, (a) 他被打了。(He is beaten by someone; ta bei da le.)(b) 弟弟被打了耳光。My brother is slapped; di di bei da le er guang.)

The subjects are both personal patient which do not have the property of patient in human experience in nature, that is to say, we often regard personal subject as a doer rather than a patient so when the personal patient have to be placed in front of the passive sentence, we have to add a marked term bei(被) after the personal patient and before the verb. When we take the figure-ground theory into consideration, the sentences in sentence (a) and sentence (b) are all explainable in logic. “他”(he) in sentence (a) as a personal patient is against people's experience so when it is put in front of the sentence, it becomes the focus and figure, and also the object(agent) is omitted for the focus of people is not on it.

\section{Chinese Agentful Passives and Figure-ground Theory}

However, sometimes we should take the agent into account, for example, 我被妈妈骂了一顿。(I was scolded by my mom; wo bei ma ma ma le yi dun.) In this sentence with the appearance of the agent, people on longer pay attention to " who was scolded" but " who scold me". Therefore, when the agent appears in prototypical Chinese passives, the agent is the figure for people's focus on it while the patient in the position of the subject is the ground.

Therefore, we can find that in both prototypical English and Chinese passives, people place their focus on the patient (subject) in agentless passives and on agent in agentful passives. In other words, the patient is expressed as the figure in agentless passives while as the ground in agentless passives.

\section{ENGLish AND Chinese NON-PROtotypicAl PASSIVES BASED ON FIGURE-GRound ThEORY}

\section{A. English Non-prototypical Passives}

English non-prototypical passives are also widely used in daily life. They are different from prototypical passives in many ways generally divided into four categories:

\section{Stative Passives and Figure-ground Theory}

Stative passives is expressed by construing a causative event as a stative event. The form of stative passives is almost same to the form of prototypical passives as $N P+b e($ copular) $+V$-en except for $V$-en is the adjective. For example: The book was lost.

In this sentence, the stative passives indicate the final state of " the book" due to a change "was lost" In the surface structure, we can find that "lost" is treated as an adjective but it implies the inherent property of an entity which indicate a change from "own" to "lost". If we take figure-ground theory into consideration, we can find that this sentence is in the same situation to the English agentless prototypical passives that both the agent and patient appear, and the subject is the agent while the patient is omitted. If it is added an agent like The book he bought was lost, inversely, this explanation also take effect as English prototypical agentful passives that"he" becomes the figure while "the book" is the ground.

\section{Get-passives and Figure-ground Theory}

It is known to all that Get-passives is often used in oral communication as an auxiliary in English passives. As we have mentioned before, we have a form of English prototypical passives: $N B+b e+V e n$. Here, "be" is stative as an auxiliary, In the prototype, "be" as an auxiliary is stative. Get-passive are mostly dynamic instead of being static. The dynamic nature of the get-passive means that the passive subject in get-passives is more or less responsible for the action or involves some control on the event. (Xu Fang, 2006) Therefore, we may draw a conclusion that in get-passives people may concentrate more on the subject(patient) for his action involves some control on the the event. We can call such state of control the salience and the figure, and the omitted agent ground, which is similar to the English prototypical passives.

For example: We got fired. In this sentence, "got" displays a dynamic scene which is quite different from "be" providing a static scene. But they all emphasize the state of the subject (patient) and regard it as the figure.

\section{3. "it + is + Ven + that" Passives and Figure-ground Theory}

In some English passives, it is difficult to find the agent or it is inappropriate to mention the agent or it is in the need of rhetoric without agent so people tend to use some frequently-used passive sentence frames leading by "it" in sentence structure"it + is + Ven+ that" to express their ideas, such as "it is said that", "it is acknowledged that", "it is reported that" etc. (Zhang Furong, 2013)

However, why would some people like to use such sentence structure in some situations in daily life? Because people do not want to clearly speak out the agent under some situations for some reasons, e.g. the speaker does not want to leave listeners an expression that his attitude is so objective to believe or the speaker does not want to mention the real 
speaker who expresses the attitude. For instance, it is said that he is the greatest hero in the world. It is obvious that the speaker or writer does not want to tell people "who said", and he just wants to express an attitude of his own to a great extent. Thus, people will focus more on his attitude than the speaker who said the sentence, so we can say the sentence after "that" is the figure and the omitted speaker is the ground. However, if we use "somebody" to replace "it", people will pay much more attention on "who said" than the following attitude. The speaker becomes prominent and is regarded as the figure while the following attitude as the ground.

\section{Notional Passives and Figure-ground theory}

In English, there is one sentence called notional passives that the structure form is active but the meaning is passive for example: these TV sets don't sell well. There is no passive marker like "be" or "get", but we can clearly understand "TV" is the patient and it cannot "sell" itself but sold by somebody. If we change the sentence into a formal passive, it goes like this: these TV sets has not been sold well. The former one implies that the TV sells bad due to the problem of the TV such as quality and price while the latter one implies that the TV sells bad because of the problem of the salesman such as carelessness and bad temper. (Jiao Xiaoting \& Kou Qin, 2002)

The stative passive is a topic-comment construction. Generally speaking, the Chinese sentence can be divided into two broad categories: subject-predicate and topic-comment. A subject-predicate sentence which signifies an event is usually used for narrative purposes; a topic-comment sentence, rather than narrating an action or event, usually provides a description or offers an opinion.

If we put figure-ground theory into explanation, we may find that the agent of these two passive sentences is omitted in that the speaker does not want to mention the agent and look it as the ground, and only emphasis the TV.

\section{B. Chinese Non-prototypical Passives}

Chinese non-prototypical passives is composed of stative passives and medio-passive: patient-NP+V(受/遭/得到, etc) ( Zhao Li, 2010)

\section{Stative Passive and Figure-ground Theory}

Stative passives can be called notional passives as well, which is same to English notional passives that the structure form is active but the meaning is passive. Chinese native speaker are apt to focus on the subject so they prefer to the use of notional passives.

For example, (a)电视机买了。(The TV he wants has been bought; ni yao de ag u shu mai le.) (b)树砍了。(The tree is cut; shu kan le.)

Based on the analysis above, in sentence (a) and (b): “买(buy; mai)" and “砍(buy; kan)" can represent both an action and a result, but “买了(have/has been bought; mai le)" and “砍了(have/has been cut; kan le)" mean that the action has finished and now it is stative.

Besides, we can find that the subject must be inanimate objects or people's experience before. In (a), it is a thinking pattern of human beings that inanimate objects usually cannot do an action that should be done by humans on its own. Hence, on the basis of human experiences, there must be a man who is supposed to buy the TV. Although there is no marked term like 被(bei), it is still regarded as the passives. In (b), 树(the tree;shu) is often being looked as patient in experience when they will be cut. On the basis of these analyses, in sentences like the examples, the subject is regarded as the figure because people do not care about the agent who is put in a secondary position.

\section{Medio-passive and Figure-ground Theory}

It is so similar to one category of English non-prototypical passives: Get-passives. In Chinese prototypical passives, not only “被(bei)”can be the auxiliary, but “受(shou)”, “遭(zao)”, “得到(de dao)” and the like are also used to serve the function, which is called medio-passive: patient-NP+V(受/遭/得到, etc). For example:

(a) 听完他的讲述, 我的内心受到很大鼓舞。(After his narrating, I was inspired so much; ting wan ta de jiang su, wo de nei xin shou dao hen da gu wu.)

(b) 小明遭到公司的不公正对待。(Xiao Ming was treated unfairly by his company; xiao ming zao dao gong si de bu gong zheng dui dai.)

(c) 长久以来, 该理论不断得到丰富和发展。(For such a long time, the theory has been increasingly enriched and developed; Chang jiu yi lai, gai li lun bu duan de dao feng fu he fa zhan.)

As can be seen from above, the medio-passives do not contain any passive marker; their passive meaning is mainly realized through the verbs in their constructions. We can find that our focus is on“我的内心”, “小明”, and“该理论”, that is to say, we regard them as the figure to be prominent, and other things around them are degraded as the ground. We come to know the ground in that we want to know the figure better.

\section{Some Similarities And Differences And Some Suggestion On ENGLish LeARning ANd TeACHING}

On the basis of figure-ground theory to comparatively study Chinese and English passives, we can analyze some similarities and differences between Chinese and English passives after the study above. Speaking of the similarity, the deep mechanism of English and Chinese passives is consistent. In prototypical passives, due to the similar structure “ $\mathrm{NP}+\mathrm{Be}+\mathrm{Ven} / \mathrm{N}+\mathrm{v}^{x^{2}}+\mathrm{V}$ ", both in Chinese and English passives the subject(patient) is the figure while the object(agent) is the ground. The similarity also reveals that English people and Chinese 'thoughts about the salience or prominence of 
something in passives are nearly the same. When they do not want to mention the agent or it is difficult to figure out the agent, both English and Chinese are apt to omit the agent as the ground in the sentences; when they want to highline the agent, they will recover the ground of the agent.

In non-prototypical passives, both English and Chinese have a category of stative passives. They are concentrated on non - prototypical passives. In Chinese notional passives, the subject is certain which means it has a related entity, and the verb is usually a transitive verb followed by adverbial or complementary or auxiliary. While nearly all English notional passives are led by an intransitive verb which is followed by some adverbials like well and easily. They two both share the same definition that the meaning is passive but the structure is active. Taking figure-ground theory into consideration, both English and Chinese passives keep the principle that because inanimate subject and the following verb are naturally passive relation so people focus on the patient and do not care about what the agent is.

Another category that both of them have is the medio-passives, and the only difference is that the signs are different but the meaning they transmits is the same. Their subject (patient) is the figure.

Speaking of the differences, we can find that the use of English passives is in a higher frequency than Chinese in that English and Chinese are distinct is that people from those two language backgrounds holds different perspectives. English native speakers tend to focus on the object while Chinese native speaker are apt to focus on the subject. That is to say, in English passives the object is often being promoted to be the figure and the subject is degraded as the ground. While Chinese often use the way of Stative Passives in daily life and prototypical passives are used in a lower frequency in that they get used to use active expressing way so that their principle of prominence is on subject as the figure.

No matter what kind of passive sentence structures in Chinese and English, both Chinese and English people have a similar institution about what to highlight, and their cognition of prominence in passives is almost the same. That's why we can correctly and accurately understand the English passives and grasp the focus in that they share the same cognitive pattern of focus in passives.

Therefore, in English learning and teaching, we should fully take advantage of those similarities and promote the positive transfer. When teaching English passives, teachers are supposed to do a comparative teaching based on figure-ground theory. In this way, students can have a better understanding of English passives from a cognitive way not simply study the grammatical knowledge.

\section{CONCLUSION}

This paper aims to discover some similarities and differences between English so that can reveal the deep mechanism of differences between Chinese and English passives from the angle of figure-ground theory in Cognitive linguistics. Figure-ground theory based on principle of prominence has a very powerful explanation force to English and Chinese passives. With a better understanding about how figure-ground theory is used to explain passives, teachers can guide students to learn passives in an effective way if he knows similarities and differences of principle of prominence in both English and Chinese; the ability of learners to use a language and cross-language contrastive analysis can be improved.

\section{REFERENCES}

[1] C.-T. James Huang \& Y-H. Audrey LiYafri Li. (2009). The syntax of Chinese. New York: Cambridge University Press.

[2] Feng Fang. (2009). A cognitive contrastive study of English and Chinese passive categories. Master degree thesis, Fujian Normal University.

[3] Huang Guangping. (2011). A cognitive analysis of English and Chinese passives from the angle of Figure-Ground theory. Journal of Central South University of Forestry \& Technology (Social Science), 5(6), 52-53.

[4] Huang Xueqiang. (2011). A construction-based contrastive study offunctions of English and Chinese passive voice-based on Be construction and Bei construction. Master degree thesis, Guangxi University.

[5] Jiao Xiaoting \& Kou Qin. (2002). On comparison between the notional passive sentences of English and Chinese. Journal of Northwest Sci-Tech University of Agriculture and Forestry (Social Science), 2(2), 82-84.

[6] Kuang Fangtao \& Wen Xu. (2003). Realization of Figure-Ground. Journal of Foreign Languages, (4), 24-31.

[7] Ni Wei \& Shao Zhihong. (2004). A cognitive constrastive study of English and Chinese. Journal of Sichuan International Studies University, 20(5), 128-133.

[8] Ungerer, F. \& Schmid. (2008). An introduction to cognitive linguistics. London: Longman.

[9] William Croft \& D. Alan Cruse. (2004). Cognitive linguistics. New York: Cambridge University Press.

[10] Xiong Xueliang \& Wang Zhijun. (2001). A cognitive-based contrastive study of English and Chinese passives. Foreign Language Research, (3), 1-6.

[11] Xiong Xueliang \& Wang Zhijun. (2002).A protype study of English and Chinese passives. Foreign Languages Research, (1): $19-23$.

[12] Xu Fang. (2006). A prototype study of the passive voice in English. Master degree thesis, Hunan Normal University.

[13] Zhang Furong. (2013). Comparative study of English and Chinese passive sentences from a cognitive perspective. Journal of Jiamusi Education Institute, (7), 375-376.

[14] Zhao Li. (2010). A prototype constrastive study of English and Chinese passive voice. Master degree thesis, Zhengzhou University. 
Bo Li was born in Luzhou, Sichuan, China in 1987. He is going to receive his Master Degree in 2016.

He is currently studying in College of International Studies, Southwest University, China and. He majors in English Language and Literature. His research interest lies in cognitive linguistics. 